\title{
New-onset diabetes after transplantation: remaining issues to be discussed
}

\author{
Li-Ying Sun ${ }^{1,2,3}$ \\ ${ }^{1}$ Department of Critical Liver Diseases, Liver Research Center, Beijing Friendship Hospital, Capital Medical University, Beijing, China; ${ }^{2}$ Liver \\ Transplantation Center, National Clinical Research Center for Digestive Diseases, Beijing Friendship Hospital, Capital Medical University, Beijing, \\ China; ${ }^{3}$ Clinical Center for Pediatric Liver Transplantation, Capital Medical University, Beijing, China \\ Correspondence to: Li-Ying Sun. Department of Critical Liver Diseases, Liver Research Center, Beijing Friendship Hospital, Capital Medical University, \\ Beijing, China; Liver Transplantation Center, National Clinical Research Center for Digestive Diseases, Beijing Friendship Hospital, Capital Medical \\ University, Beijing, China; Clinical Center for Pediatric Liver Transplantation, Capital Medical University, Beijing, China. Email: sunxlx@outlook.com. \\ Comment on: Man Kim J, Hwang S, Lee KW, et al. New-onset diabetes after adult liver transplantation in the Korean Organ Transplantation Registry \\ (KOTRY) study. Hepatobiliary Surg Nutr 2020;9:425-39.
}

Submitted Sep 22, 2021. Accepted for publication Oct 18, 2021.

doi: $10.21037 / \mathrm{hbsn}-21-397$

View this article at: https://dx.doi.org/10.21037/hbsn-21-397

With the continuous development of the surgical techniques of liver transplantation, patients' quality of life during the posttransplant period has also improved. Specialists have become more concerned about long-term complications after liver transplant (LT), which seriously affect the longterm survival of LT patients.

New-onset diabetes after transplantation (NODAT) is one of the major complications occurring in patients who were not diabetic before transplantation. The standardized diagnostic American Diabetes Association criteria are preferred for the diagnosis of NODAT, which is an important longterm complication of transplant recipients. Previous studies have indicated that NODAT is associated with increased cardiovascular events and impaired recipients and grafts (1). Although researchers have studied various aspects of NODAT, and some general findings have been compiled from the reports of different countries, races, and transplantation centers, some controversy remains across these results.

Multiple risk factors of NODAT were revealed in previous studies. The characteristics of liver transplantation recipients, such as older age, higher body mass index (BMI), hepatitis $\mathrm{C}$ virus (HCV) and other virus infections, male gender, fasting plasma glucose (FPG) level before transplantation, and ethnic differences are all risk factors for NODAT (2-4). Postoperative treatment and medication related to liver transplantation include corticosteroid shock therapy, tacrolimus, and mTOR inhibitor. Some studies have shown associations with donor factors (5). Hartog et al. found that the incidence of NODAT in LT recipients who received donated after circulatory death (DCD) grafts was higher than that in patients who received donated after brain death (DBD) in the early postoperative stage (within 15 days) (6). They also found that recipient age and pulse steroid therapy were risk factors for postoperative NODAT. In the study by Honda et al., steroid pulse therapy and liverto-spleen (L-S) ratio in living donor liver transplantation (LDLT) recipients were the identified risk factors of NODAT (7). We have examined 23 relative studies in the last decade and summarized the risk and protective factors of NODAT. The results are shown in Figure 1. There are few studies about the protective factors of NODAT, which have revealed that basiliximab induction, antimetabolite therapy, and LDLT might prevent NODAT after LT $(5,8)$.

Our interest was piqued by the paper of Man Kim et al. (9). The data in this article are from the Korean Organ Transplantation Registry (KOTRY), which included 1,919 LT recipients. In their study, the incidence of NODAT at 6 and 12 months after LT was $19.6 \%$ and $20.8 \%$, respectively. Some of the results are similar to those of previous studies; for example, older recipients, higher BMI receptors, and steroid use are predictive factors for NODAT. They found that open donor hepatectomy and small size liver transplantation (graft to recipient weight ratio; GRWR $\leq 0.8$ ) were closely associated with NODAT in LDLT 


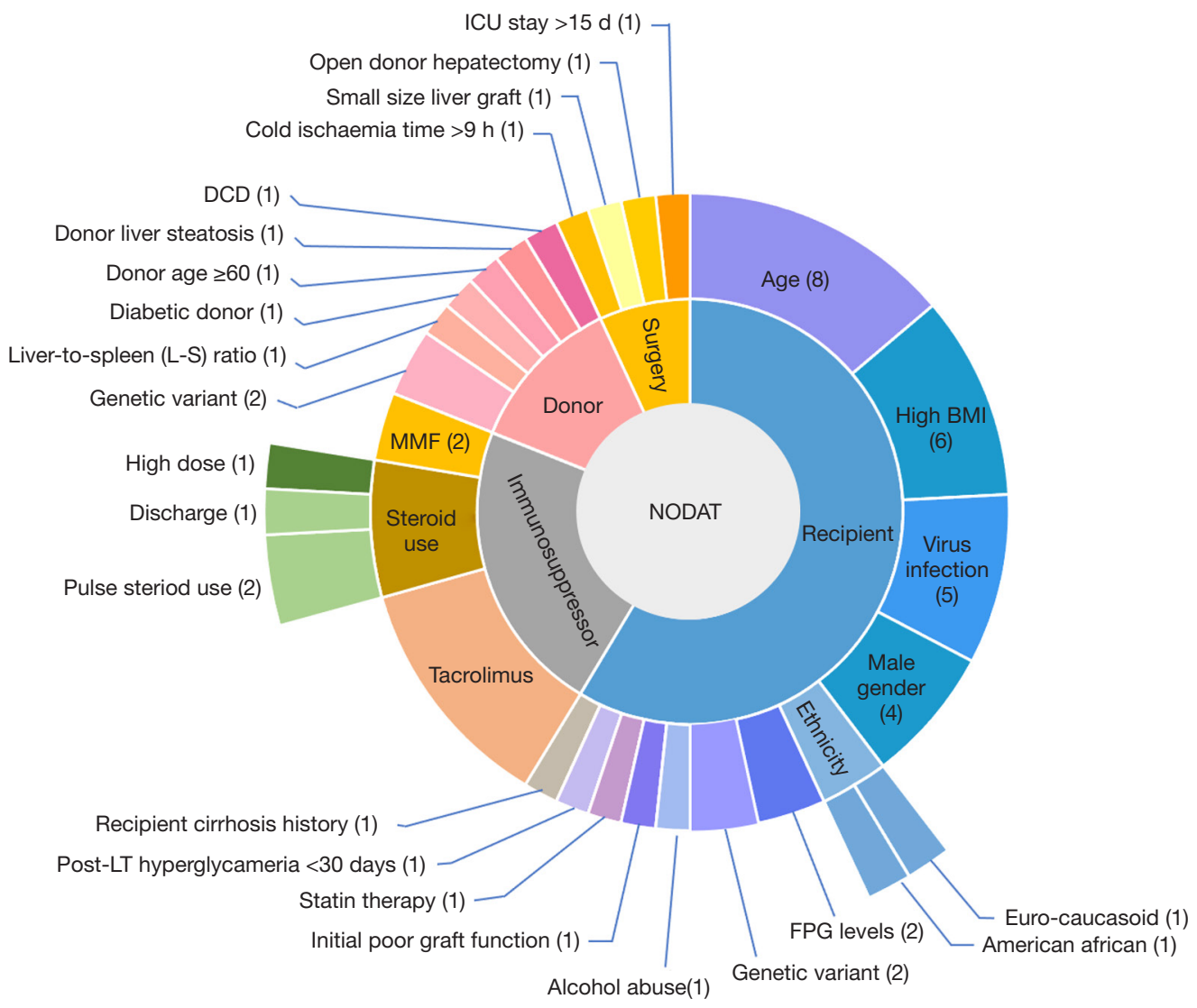

Figure 1 The risk factors of NODAT in the literature of the last decade, the figures in parentheses refer to the number of papers. "small size liver graft" and "open donor hepatectomy" are revealed by Man Kim et al.

recipients. In addition, the use of antimetabolic drugs and basiliximab protected adult LT recipients from NODAT. In their study, the use of mTOR inhibitors (mammalian target) 6 months after LT did not increase the risk for NODAT, which is different from the previous study (10). One of the most unique results was that small grafts are closely related to NODAT in adult liver transplantation, while minimally invasive donor hepatectomy has a protective effect on NODAT. The same results have not been reported in any other published studies so far.

Concerning the mechanism of NODAT, it is easier to explain the more generally accepted indicators such as steroids therapy, calcineurin inhibitors, and the high BMI associated with obesity. The use of corticosteroids will produce insulin resistance and lead to an increase in liver gluconeogenesis. Calcineurin can impair islet $\beta$-cell function, induce insulin resistance, and seriously affect peripheral glucose utilization, resulting in abnormal glucose metabolism (11). Ling et al. revealed that tacrolimus or hyperglycemia altered liver microRNA (miRNA) profile, which is associated with insulin resistance and glucose homeostasis imbalance (12). They also found that miRNA expressive patterns of disease susceptibility can be imported directly from donors and integrate the expression pattern with the recipient through the graft.

However, this literature did not elucidate the mechanism that the small graft and open hepatectomy could increase the incidence of NODAT, while minimally invasive donor hepatectomy has a protective effect. The authors speculate that the inflammatory response of the liver after hepatectomy and liver regeneration may lead to the release of cytokines and increased lipid peroxidation (13). We strongly support that further research in this area is required. Nonetheless, we noticed that this study involved data from 15 transplant centers registered in the KOTRY, among which, 3 to 5 centers performed laparoscopic surgery for a partial living donor liver. All the cases in the author's center were obtained by laparoscopy. If the center 
without minimally invasive donor liver acquisition had not reported NODAT cases, it might increase the possibility of deviation in the results. So expanded research at centers in other countries may further confirm this novel finding.

The treatment of NODAT can be through weight control, reasonable diet structure, reducing the application of glucocorticoids, and the application of antihyperglycemic agents. The most commonly used are insulin secretagogues, metformin, pioglitazone, and so on. Glucagon-like peptide-1 receptor agonists (GLP-1RAs) is a novel antidiabetic drug. Although there is no data on NODAT treatment by GLP1RA, it has been researched and reported in kidney and pancreas transplantation (14), which provides a reference for the treatment of NODAT. The main challenges in the treatment of NODAT are the interference with the blood concentration by immunosuppressants, the impact on graft function, and whether it increases the cardiovascular risk of patients. Long-acting GLP-1RAs is eliminated through enzyme degradation and renal clearance. Therefore, the interaction with immune reagents and the impact on drug concentration are avoided, and the dosage of immune agents does not need to be adjusted. This is very important for posttransplant patients. Both doctors and patients should put more focus on NODAT. This study did not show any difference in graft survival between NODAT patients and non-NODAT patients. However, NODAT was reported to affect the survival of recipients in previous studies $(1,11)$. We believe that more clinical data and experience in the treatment of NODAT will be published in the next few years.

\section{Acknowledgments}

Funding: None.

\section{Footnote}

Provenance and Peer Review: This article was commissioned by the editorial office, Hepatobiliary Surgery and Nutrition. The article did not undergo external peer review.

Conflicts of Interest: The author has completed the ICMJE uniform disclosure form (available at https://hbsn. amegroups.com/article/view/10.21037/hbsn-21-397/coif). The author has no conflicts of interest to declare.

Ethical Statement: The author is accountable for all aspects of the work in ensuring that questions related to the accuracy or integrity of any part of the work are appropriately investigated and resolved.

Open Access Statement: This is an Open Access article distributed in accordance with the Creative Commons Attribution-NonCommercial-NoDerivs 4.0 International License (CC BY-NC-ND 4.0), which permits the noncommercial replication and distribution of the article with the strict proviso that no changes or edits are made and the original work is properly cited (including links to both the formal publication through the relevant DOI and the license). See: https://creativecommons.org/licenses/by-nc-nd/4.0/.

\section{References}

1. Pelaez-Jaramillo MJ, Cardenas-Mojica AA, Gaete PV, et al. Post-Liver Transplantation Diabetes Mellitus: A Review of Relevance and Approach to Treatment. Diabetes Ther 2018;9:521-43.

2. Lv C, Zhang Y, Chen X, et al. New-onset diabetes after liver transplantation and its impact on complications and patient survival. J Diabetes 2015;7:881-90.

3. Lawendy B, Srinathan S, Kotha S, et al. Systematic review and meta-analysis of post-transplant diabetes mellitus in liver transplant recipients. Clin Transplant 2021;35:e14340.

4. Gebhardt S, Jara M, Malinowski M, et al. Risk factors of metabolic disorders after liver transplantation: an analysis of data from fasted patients. Transplantation 2015;99:1243-9.

5. Kuo HT, Sampaio MS, Ye X, et al. Risk factors for newonset diabetes mellitus in adult liver transplant recipients, an analysis of the Organ Procurement and Transplant Network/United Network for Organ Sharing database. Transplantation 2010;89:1134-40.

6. Hartog H, May CJ, Corbett C, et al. Early occurrence of new-onset diabetes after transplantation is related to type of liver graft and warm ischaemic injury. Liver Int 2015;35:1739-47.

7. Honda M, Asonuma K, Hayashida S, et al. Incidence and risk factors for new-onset diabetes in living-donor liver transplant recipients. Clin Transplant 2013;27:426-35.

8. Carey EJ, Aqel BA, Byrne TJ, et al. Pretransplant fasting glucose predicts new-onset diabetes after liver transplantation. J Transplant 2012;2012:614781.

9. Man Kim J, Hwang S, Lee KW, et al. New-onset diabetes after adult liver transplantation in the Korean Organ 
Transplantation Registry (KOTRY) study. Hepatobiliary Surg Nutr 2020;9:425-39.

10. Bhat V, Tazari M, Watt KD, et al. New-Onset Diabetes and Preexisting Diabetes Are Associated With Comparable Reduction in Long-Term Survival After Liver Transplant: A Machine Learning Approach. Mayo Clin Proc 2018;93:1794-802.

11. Markell M. New-onset diabetes mellitus in transplant patients: pathogenesis, complications, and management. Am J Kidney Dis 2004;43:953-65.

12. Ling Q, Xie H, Li J, et al. Donor Graft MicroRNAs: A

Cite this article as: Sun LY. New-onset diabetes after transplantation: remaining issues to be discussed. HepatoBiliary Surg Nutr 2021;10(6):906-909. doi: 10.21037/hbsn-21-397
Newly Identified Player in the Development of New-onset Diabetes After Liver Transplantation. Am J Transplant 2017;17:255-64.

13. Mendes-Braz M, Martins JO. Diabetes Mellitus and Liver Surgery: The Effect of Diabetes on Oxidative Stress and Inflammation. Mediators Inflamm 2018;2018:2456579.

14. Halden TA, Egeland EJ, Asberg A, et al. GLP1 Restores Altered Insulin and Glucagon Secretion in Posttransplantation Diabetes. Diabetes Care 2016;39:617-24. 